\title{
Illusions of Balance and Control in an Always-On Environment: A Case Study of BlackBerry Users
}

\author{
Catherine A. Middleton
}

Ryerson University

digital.library.ryerson.ca/object/355

\section{Please Cite:}

Middleton, C. A. (2007). Illusions of balance and control in an always-on environment: A case study of BlackBerry users. Continuum: Journal of Media and Cultural Studies, 21(2), 165-178.

doi:10.1080/10304310701268695

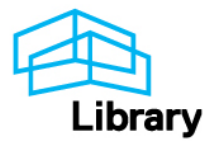




\title{
Illusions of Balance and Control in an Always-On Environment: A Case Study of BlackBerry Users
}

\author{
Catherine A. Middleton \\ School of Information Technology Management \\ Faculty of Business \\ Ryerson University \\ Toronto, Canada \\ cmiddlet@ryerson.ca
}

This is an electronic version of an article to be published in Continuum: Journal of Media \& Cultural Studies (Special Issue on Mobile Communication).

http://www.tandf.co.uk/journals/titles/10304312.asp 


\section{Illusions of Balance and Control in an Always-On Environment: A Case Study of BlackBerry Users}

\section{Introduction}

This paper presents a qualitative case study of Canadian BlackBerry ${ }^{\circledR}$ users. It begins with a brief description of the BlackBerry, a handheld wireless mobile email device developed by Research in Motion ${ }^{1}$. BlackBerry users find their devices to be empowering, allowing them more control over their environments. The BlackBerry does give its users a mechanism to exert control over the management of daily communication tasks, but by virtue of its always-on, always-connected nature, it also reinforces cultures that expect people to be accessible outside normal business hours. Rather than just a tool of liberation for its users, the BlackBerry can also be understood as an artifact that reflects and perpetuates organisational cultures in which individual employees have little control and influence. While this case study focuses on BlackBerry users, it is suggested that the findings are not unique to this device. BlackBerries and other mobile technologies have been envisioned by some as means of enforcing work-life boundaries, but this paper concludes that the use of always-on mobile devices can lead to situations where conflict between work and personal activities is exacerbated rather than reduced.

Since its launch in 1999, the BlackBerry has established itself as the mobile email device of choice for business and government sectors ${ }^{2}$. Although it offers a mobile phone, calendaring, contact and task management, and web browsing, the main reason for having a BlackBerry is to send and receive emails. The device has been very successful in providing easy to use, always-on, reliable email connectivity from virtually anywhere ${ }^{3}$.

Unlike competing devices, the BlackBerry embodies a distinct cultural identity, and has become part of the 'cultural universe' (Du Gay, Hall, Janes, Mackay \& Negus, 1997) in North America and beyond ${ }^{4}$. The BlackBerry has been the subject of much attention in the popular press ${ }^{5}$. Stories about BlackBerry usage are often predictable, offering anecdotes of users who cannot be separated from their devices, discussions of the addictive nature of the devices (frequently invoking the word 'Crackberry'), and identification of aggrieved spouses, partners or colleagues who resent the BlackBerry's intrusiveness (e.g. Economist Staff, 2005; Parks, 2006; Terry, 2006).

Curiosity about such extreme reactions to a simple mobile device prompted a study of Canadian BlackBerry users. Initial analysis showed how mobile email usage can be both dysfunctional and functional, arguing that assessment of mobile email is influenced by organisational culture (Middleton \& Cukier, 2006, in press). In this paper, Schein's (2004) model of organisational culture is applied as a means of further exploring the cultural values and assumptions that influence patterns of BlackBerry use. The cultural framework can help to reconcile the disparate perceptions of the BlackBerry by showing how these perceptions are embedded in different layers of cultural understanding. When examined as a cultural artifact, the BlackBerry is a tool of efficiency, providing control over users' communication needs from any location, and enabling responsiveness and accessibility at all times. Examining the values that encourage these usage patterns allows identification of work intensification and work extension practices. In turn, these routines reflect organisational cultures in which it is assumed that employees are available in times and places extending well beyond office hours. The paper concludes by discussing the culture of BlackBerry usage within the context of work-life balance research, suggesting that the adoption of mobile technologies may lead to increased work-life conflict, 
resulting in detrimental organisational outcomes.

\section{Literature Review}

There is an extensive body of work discussing consumer usage of mobile technologies, with a particular focus on mobile telephony (see for example Brown, Green \& Harper, 2002; Fortunati, 2002; Gordon, 2002; Haddon, 1997; Humphreys, 2005; Katz, 2003; Katz \& Aakhus, 2002; Ling, 2004; Nyíri, 2003; Oksman \& Turtiainen, 2004; Peters \& Allouch, 2005). In contrast, there is limited academic work on organisational usage of mobile email. In the past few years, BlackBerries have become commonplace among business users, and their attributes have become known to the general public (especially as a patent dispute threatened to shut down the service, see BlackBerry Blackout, 2005), but the devices have received limited notice in studies of technology usage by mobile professionals. Nah, Siau and Sheng (2005) and Sørensen and Gibson (2004) do note the BlackBerry's perceived value.

Allen and Shoard (2005) investigated whether BlackBerries would be effective in managing email overload. Their results indicated that adoption of BlackBerries did not reduce perceived overload, but did allow users (senior police officers) greater control over their email because they could read and respond to it throughout the day, regardless of whether they were in the office or not.

Mazmanian, Orlikowski and Yates (2005) reported that mobile email users were expected to, and did, respond more quickly to email than people who did not have access to a mobile device $^{6}$. Users reported 'constant and sustained interaction with their devices' (p. 340), using them to monitor their work environments. The users valued the increased connectivity that the devices enabled, but reported spousal resentment toward the intrusions such connections created.

Jarvenpaa, Lang and Tuunainen's (2005) work noted user ambivalence to mobile technologies in a series of paradoxes. For example, mobile technologies both empower and enslave users, simultaneously engage and disengage them, and blur the boundaries between private and public space and communication.

Middleton and Cukier's (2006, in press) initial analysis of mobile email showed how it could be constructed as functional and dysfunctional. For instance, in the name of efficiency (a functional attribute) mobile email users carried out dangerous practices (e.g. emailing while driving, an example of a dysfunctional use of mobile email). Minimally disruptive behaviours were also considered anti-social, the immediacy of mobile email could be distracting, and by liberating users from the confines of work, mobile email delivered work to the home and to other nonwork environments, challenging work-life boundaries.

Cousins and Robey (2005) addressed the issue of boundary control in their study of nomadic work patterns, concluding that the workers they studied used mobile technologies in ways that sharpened and reinforced work-life boundaries. But while these respondents may have believed that they were keeping work time and personal time separate by defining clear boundaries, it seems that work time was dominant for at least some of the respondents. As such, boundaries may have been maintained, but it is not clear that such boundaries resulted in balance between work and personal activities.

Govindaraju and Sward (2005) also argued that mobile technologies can enable work-life balance. By 'time slicing' (using very small portions of time to do work activities), people could be productive even when they only had a few minutes to spare. Time was also 'shifted', 
allowing people to move work around during the day to accommodate personal activities. The researchers expressed concern that the availability of mobile technologies that increased people's ability to work anywhere would be perceived as encroaching on personal time, but their respondents (Intel employees) felt that the increased flexibility was beneficial.

There are advantages (mobility, remote control over work) and disadvantages (accessibility, blurred work-life boundaries) that accrue to users as they adopt mobile technologies. This paper offers further investigation into the relationship between mobile technologies and worklife balance, an important issue as the adoption of always-on devices like BlackBerries becomes more prevalent in the work place.

\section{Research Methodology}

Data presented here come from semi-structured, qualitative interviews conducted with thirteen Canadian BlackBerry users, as part of a larger study exploring contradictions of mobility (described in Middleton, Scheepers \& Cukier, 2005). Respondents were identified by the author and a colleague through their networks of business contacts, with those participating in the study representing a variety of industries, differing levels of job seniority, and ranging in age from their mid-20s to their mid-50s. Respondents were not primarily 'nomadic' or 'mobile' workers, but frequently moved around the cities in which they lived (Montreal, Ottawa, Toronto, Hamilton, Regina). Most of their jobs involved some travel. A limitation in the data set is the gender imbalance. Of the thirteen interviews discussed in this paper, only two were with female BlackBerry users.

All interviews were audiotaped and professionally transcribed. Thematic categories were established from the initial exploratory research questions, and coding was done using the qualitative data analysis software package ATLAS.ti. This paper focuses on data describing the BlackBerry as a cultural artifact, and data that outlines the routines established in using the device.

\section{The BlackBerry Experience}

The analysis adopts Schein's model of organisational culture (Schein, 2004) as a means of understanding BlackBerry use within organisations. Schein's model shows how cultures are established and perpetuated within organisations, through an exploration of artifacts, values and underlying assumptions ${ }^{7}$.

Respondents in this study come from diverse backgrounds, and at a macro level experience varied organisational cultures. In applying a cultural analysis, it is not suggested that respondents' cultures are uniform in all aspects. It is argued however, based on initial analysis of these data (Middleton \& Cukier, 2006, in press), that there is a commonality of cultural influences impacting the usage of mobile communication devices within respondents' organisations and work environments. This commonality is demonstrated in the thematic congruence observed in participants' experiences with their devices and reflects shared understandings of the value of mobile devices in their work environments.

Schein (2004, p. 8) argues that culture 'guides and constrains' behaviours within groups. Artifacts (including technologies, rituals, myths and stories) are visible manifestations of culture, 'easy to observe, and very difficult to decipher' (p. 26). To gain a deeper understanding of the way an artifact is used and understood, a study of organisational values relevant to the artifact is needed. Values reflect guiding social principles (Hatch, 1993) and can be understood by examining organisational practices and activities (Van Den Berg \& Wilderom, 2004). 
Underpinning organisational values are the 'basic assumptions' that encompass 'taken for granted,' shared understandings on which actions are premised. These basic assumptions enable the development of shared 'mental maps' that guide behaviours among group members (Schein, 2004, pp. 30-32).

\section{The BlackBerry in Action}

It is difficult to understand the level of engagement BlackBerry users have with their devices without witnessing users in action. This section offers a brief composite view of a typical BlackBerry user, drawn from user data and popular press accounts. The first thing many users do in the morning is check their BlackBerry, and the device remains with them throughout the day, until they go to bed. Some users even admit to waking up to read email in the middle of the night (Maiden, 2006). An anonymous poster to the techdirt.com website describes the BlackBerry as an 'Electronic Pet' - 'you constantly see people taking their little pets out and stroking the scroll wheel, coddling them, basically 'petting' them.' (Anonymous, 2004). It is common for BlackBerry Users to respond in a Pavlovian fashion to the beeps or buzzes that indicate the arrival of messages, grabbing at the device immediately to see what is new. In organisations with multiple BlackBerry users, notification and clicking sounds fade into the background as a familiar backdrop to business activities. BlackBerries 'turn e-mail from something you do on a computer to something you just kind of do ... you go from something that is done at a desk to something that is done wherever you are,' many, many times a day. Demonstrating that BlackBerries do go everywhere, one respondent damaged his BlackBerry when he was caught in a wave on a beach, another damaged hers when it fell into a toilet. The BlackBerry is described as a cultural artifact below, and user routines are discussed in more detail when considering the values that underpin BlackBerry usage.

\section{The Artifact}

Users' descriptions of the BlackBerry and its functionality were straightforward, focusing on its ease of use, mobility, flexibility, convenience, always-on immediacy, and reliability. As one user said, 'it simply does what needs to be done.' Despite the BlackBerry's reputation as an addictive device, the informants did not cast their devices in that light. The word 'Crackberry' was mentioned in only three interviews, twice in reference to someone else's description of the device. While several users did acknowledge the addictive qualities of their devices, it was far more common for users to emphasise and reinforce the BlackBerry's benefits. Descriptors included liberating, freeing, tremendously useful and beneficial.

\section{Values}

The terms used to describe the artifact offer insights into respondents' values about mobility. Although individuals worked for different organisations, their values were similar and led to common behaviours. Values revolved around efficiency, immediacy, accessibility, and flexibility, and were realized in the routines users adopted with their BlackBerries.

\section{Work Intensification}

Many of the respondents described using their BlackBerries in ways that intensified their working practices, so that they could accomplish additional tasks within the traditional time and space confines of their jobs. For example, the device was used as a means of silent communication when attending a meeting, allowing the user to reach out to the external world beyond the meeting. Indeed, once colleagues were aware that someone had a BlackBerry, 
being in a meeting was no longer an excuse for not responding to a message immediately.

For many respondents, the BlackBerry offered a sense of security, by allowing them to monitor situations remotely. People spoke of the ability to deal with urgent situations or 'dilemmas' by email, rather than by disrupting meetings by 'jumping out and taking the phone call.' 'Having a quick look' at the device when a new message was received provided reassurance, even if the user did not choose to open the message or reply to it. One user described the BlackBerry as being like a car 'dashboard,' allowing for a quick scan of various items. Another described it as a means of 'directing traffic,' an essential activity as he juggled the multiple demands of his job.

Although they tried to be discreet when using their BlackBerries, users were very aware of the disruptive nature of these intensified work practices. When asked about attending meetings where people did use their BlackBerries throughout, there was an air of resignation indicating that while this wasn't the optimal practice, it did allow people to manage the multiple demands on their time. One workplace had instituted a 'no BlackBerry' rule for meetings, but in others respondents rationalised their own and others' BlackBerry usage in meetings by suggesting that given the alternative of skipping the meeting, 'occasionally checking their Blackberry' was acceptable.

\section{Time-based Work Extension}

In addition to making it possible to intensify work practices, the BlackBerry made it much easier for individuals to work longer hours. While many of these individuals worked long hours before getting their BlackBerries, certain affordances of the device were particularly conducive to extending work hours. For instance, because the device has an alarm clock, several respondents reported that the last thing they did at night and the first thing they did in the morning was check their email, as the BlackBerry was at their bedside. To the dismay of partners and spouses, email monitoring behaviours continued throughout most respondents' waking hours. One user noted 'if I've misplaced my BlackBerry there's an immediate understanding around the home that I'm definitely going to be on edge until it's found.' Although some people did turn off their BlackBerries, or at least 'take them off their belts' when they got home, others kept the device active and in reach at all times. Only one organisation explicitly freed people from their devices by instituting a policy of 'no email' after six p.m. or on weekends. In contrast, others reported having 'conversations all the time with my boss at ten or eleven o'clock at night, with the BlackBerry', and 'getting Berries at all points, weekends, eight o'clock this morning and probably eight o'clock tonight.'

\section{Location-Based Work Extension}

Mobile devices are valued by many because they offer anytime, anywhere availability. In most places users simply turn on the device and email appears in the inbox. Some users were frustrated that their service provider did not offer international connectivity, but for those who did have this option, using the BlackBerry outside the country was seamless. Individuals used their BlackBerries on airplanes (turning on the transmission signal after the plane landed to send out queued messages instantly), trains, buses, and in cars and taxis. Two respondents 'berried' on their bicycles, and one person commented on almost being hit by BlackBerrywielding pedestrians not looking where they were going. (This scenario is the basis of a comedy sketch, promoting the 'BlackBerry Helmet,' see Rick Mercer Report, 2006.)

With a BlackBerry, email 'follows' the user around. Many chose to have their email follow them even while on vacation, although some were 'instructed' by their spouses to leave the device 
behind. Commenting about using his device on the golf course, one respondent noted that 'maybe you do more work, but it frees you, it just lets you get out of the office without disrupting your ability to stay connected.' Another, one of three who reported using the BlackBerry at the beach said, 'Look how empowering BlackBerry is. I can be on the beach with the family and be connected in. That is a great comfort to me.'

For these users, having a device that connected them to the office and the business environment from any location was empowering, not intrusive. That the device was on all the time was not seen as an infringement on personal time, but a means of controlling the work environment to better fit personal needs, offering liberation, freedom and peace of mind.

These routines reflect the values of BlackBerry users, and by extension offer insights into their organisations' values around mobile technologies. The routines that enabled users to intensify their work practices using mobile devices, and to work anytime and anywhere reflect organisational cultures that value immediacy, and responsiveness. No respondents spoke directly of organisational mandates requiring 'always-on' availability, but it was clear from their reflections about BlackBerry usage that being connected to their jobs well beyond the traditional 'nine to five' business hours was very important to them.

\section{Underlying assumptions}

The BlackBerry users who participated in this survey did not question their commitment to long working hours and were totally engaged with their jobs. In the organisation that discouraged evening and weekend email, employees still worked at those times. Describing his job, one respondent said, 'I love the work I do, I would be available 24 hours. ${ }^{18}$ Users accepted the fact that they were on call for up to 24 hours a day, and embraced the challenges and responsibilities of their jobs. Users got BlackBerries to help cope with the demands of their jobs.

The unspoken assumption among respondents was that the environments in which they worked created pressures to be engaged and involved with their jobs. The BlackBerry is an instrument of engagement with this environment. Using the terminology presented in a large scale study of Canadian workers, our respondents' work environments could be characterized as having a 'culture of hours' (Duxbury, Higgins \& Coghill, 2003). In this type of culture, it is understood that long working hours are necessary for success and advancement (Higgins \& Duxbury, 2005). The cultures experienced by the BlackBerry users could further be described as 'cultures of delivery' or 'cultures of performance,' where the focus is on doing 'whatever it takes' to get the job done.

\section{Reflecting on BlackBerry Users' Cultures of Mobility}

This paper uses a cultural lens to understand how the usage of a specific mobile device becomes routinised and embedded within organisations. A discussion of the BlackBerry as a cultural artifact shows the construction of the BlackBerry as a tool of efficiency. This understanding is reinforced by observed routines of usage, routines that take advantage of the device's mobility and discreet nature, combined with the power of email, to encourage work intensification, and the extension of work into times and spaces more traditionally considered non-work or personal times and spaces. The routines reflect organisational values of availability and responsiveness, which in turn reflect deep-seated organisational beliefs about employee commitment to long working hours, and to the achievement of 'results'. The tool of efficiency is also an instrument that connects employees to their organisations, facilitating and possibly encouraging long working hours. 
The interviews with BlackBerry users demonstrate their commitment to this vision of their work worlds. Although there are of course some points of resistance to this perspective, a persistent theme focused on the value of the BlackBerry in allowing its users to cope with the extended demands on their time and goodwill that are accepted as 'the nature of the job' in today's (North American) business environment. Users did acknowledge that using their BlackBerries could create intrusions, but always rationalized their usage in ways that demonstrated how the device could help to manage such intrusions.

These BlackBerry users resisted the 'Crackberry' label so frequently used by the media, and did not generally consider their usage of the device to be addictive. If they were to admit an addiction, it would likely be to their work, not to a tool they used to manage their work. Nevertheless, the tool facilitated their work addiction, by seamlessly bringing the office to the worker on a $24 / 7$ basis.

If this paper were to conclude here, it would overlook some key aspects of BlackBerry usage by individuals in organisations. Thus far, the paper has presented detailed insights into BlackBerry usage, refuting the Crackberry claims of addiction (claims made primarily by non-users), and explaining how users feel the device offers liberation and control over their work environments. This line of argument is supported by the data, and reflects a consistency in users' organisational cultures at the levels of the mobile artifact, values and underlying assumptions about mobility.

But the Crackberry idea should not be so easily dismissed. Whether users acknowledge it or not, there is a case to be made that using a BlackBerry (or any other mobile device that enables the same type of seamless 24/7, work-life integration) supports and perpetuates the very work culture that users are trying to manage and control through the device. This is an instance of Metcalf's law (Gilder, 1993), which in simple terms suggests that communication networks become more valuable the more users join them. Mobile device usage begets more mobile device usage, addictive or not. The more that individuals make themselves electronically open and available to their colleagues, clients and others, the more this availability will be exploited. Actions that appear as reasonable attempts to control a demanding job can encourage further engagement, resulting in increased, rather than decreased workload.

While it may be too strong to suggest that a crisis is looming, mobile device adoption in the workplace does facilitate situations in which work-life balance is compromised. As noted earlier, in and of themselves, neither the BlackBerry, nor similar mobile devices, further erode an already tenuous work-life balance. What is different with mobile devices as compared to older telecommuting, home-based technologies is that the mobile devices are more efficient at engaging individuals in work activities. Mobile devices have been embraced because they allow people to work anywhere, at anytime, but such affordances have the potential to increase work-life conflict.

Duxbury, Higgins and colleagues have been investigating balance and conflict among work, family and life for many years (Duxbury \& Higgins, 2001; Duxbury et al., 2003; Duxbury, Higgins \& Lee, 1994). Higgins and Duxbury (2005) reflect on this research, noting that in multiple studies since 1989, each of three elements of work-life conflict has been reported more frequently over time. It is easy to make links between these elements and the data presented above.

'Role overload' is experienced when a person has 'too much to do in the available time' (Higgins \& Duxbury, 2005, p. 1). This situation was faced regularly by the BlackBerry users in this study, 
and one response to it was to use the BlackBerry to adopt work intensification behaviours. With the BlackBerry, users tried to do more than one thing at once, so that they could cram more into their tight schedules. Work intensification was observed within the confines of their existing daily routines, and was carried out in addition to observed work extension routines. Hallowell (2005) challenges the effectiveness of work intensification practices, arguing that multitasking of this nature is not successful.

Work extension practices were not new to the BlackBerry users, many of whom worked long hours from multiple locations before they got their BlackBerries. What was different about adopting the mobile device was that it made it easier to further extend work into personal time and space. For example, having the BlackBerry beside the bed not only extended work, it also created work-family interference. Another source of work-family interference was noted when users took their mobile devices to places where earlier technologies did not function well. For example, the small size and long battery life made it possible to use BlackBerries while camping, on remote beaches, on swimming pool decks and at vacation homes.

It is very easy to toss a BlackBerry into a purse or clip it onto a belt, meaning that the user is rarely without it. For this reason, in addition to work-family interference, BlackBerry users also experienced family-work interference. As one young father explained, 'work follows you home, home follows you to work,' adding that 'for me that's been a good thing.' Many users commented on instances where their device brought a family or personal issue into their work environment, and this was not perceived as being disruptive. Among this particular group of users there were fewer instances of family-work overlap than of work-family overlap, which is perhaps a reflection of the gender imbalance among the respondents. (For example, Chesley (2005) found that mobile phone usage was associated with increased negative family-work 'spillover', or imbalance, in women, but not in men, although phones were associated with increased negative work-family spillover for both genders.)

These data on BlackBerry usage fit well with research on work-life conflict. Work intensification practices can be understood as a response to role-overload. Work extension practices put stress on work-family relationships, increasing the potential for conflict as mobile devices became an unwelcome part of their users' personal lives (unwelcome at least to those around them). Family-work interactions were supported by the mobile devices, and did not appear to be problematic.

Duxbury, Higgins and Lee (1994) explain that work-life stress is mitigated by perceived control. This relationship provides a plausible explanation as to why the respondents constantly rationalized as acceptable what appeared to be intrusive uses of their devices. An outside observer could easily conclude that behaviours like reading email at midnight, or checking in with the office before getting out of bed in the morning are indicative of work-life conflict. But the source of conflict is in the work, and the device is used in an attempt to control the demands of the job. Nevertheless, it is hard to imagine that even if a person is choosing to work at midnight and first thing in the morning that such behaviours reflect a balanced work-life environment.

Looking at BlackBerry usage in the context of work-life balance helps to provide perspective on the behaviours reported here. For most users, BlackBerries are not helping in achieving worklife balance. Despite the sense of control enabled by BlackBerries, their always-on nature encourages behaviours that make it easy to do more work and spend less time pursuing personal and family activities. 
It is beyond the scope of this paper to address the implications of decreasing work-life balance. This topic is the subject of an extensive report by Duxbury and Higgins (2001), in which they clearly outline the negative societal consequences of work-life conflict and offer remedies for employers, employees and government to begin addressing the situation.

\section{Conclusions}

The paper started with the observation that BlackBerries are loved by their users yet frequently loathed by their users' closest friends and relations. Data were presented to show why BlackBerries were so highly regarded by their users, demonstrating their versatility in supporting anywhere, anytime work practices, and enabling users to be more efficient and to do more work throughout their busy days. Users explained that their BlackBerries are tools to help them control and manage their work environments. They acknowledged working long hours, but loved their jobs and valued the flexibility that their BlackBerries offered to manage their work on their own terms. The data offer a compelling argument as to why BlackBerries have become so prevalent in business and government circles in North America.

But the paper also argues that situation is not as positive as it might appear at first glance. Without directly challenging the opinions of the people who participated in this study, it is suggested that their perceptions of acceptable engagement levels with their mobile devices are influenced by organisational cultures that reinforce overwork and promote unrealistic expectations for employee engagement in their jobs. The respondents' beliefs that justify and rationalise their usage of their BlackBerries at all times of day and night, from all over the world, whether working or on vacation are sincere and appear to be deeply internalized. But this paper provides an interpretation of these beliefs that shows how they are shaped by arguably unreasonable organisational demands and expectations regarding employee commitment and accessibility.

The paper considers these findings from the work-life balance perspective, observing that work extension and intensification behaviours are likely to increase work-life conflict. It is suggested that over time, the widespread adoption of mobile technologies may result in detrimental organisational outcomes, unless organisations are better able to manage employee workloads and set reasonable expectations for engagement with mobile devices.

A potentially interesting line of inquiry for future research in this area would be to investigate mobile device usage through an organisational learning perspective. The question of interest here would be how do organisations and the individuals in them learn to cope with what are likely to be the increasingly negative impacts of mobile technology adoption in the workplace. Can organisations practice 'double loop learning' (Argyris \& Schön, 1978) to reassess and adjust their courses of action? Are organisations trapped in feedback loops that reinforce the negative aspects of always-on connectivity, or can they 'learn' to change (Senge, 1990)? Do organisations face 'escalating commitment' to courses of action (Staw, 1981), and if so, can they resolve such situations appropriately?

In closing, it is reiterated that the issues discussed here are not just BlackBerry issues. Problems of overwork and imbalance between personal and work commitments have been a part of (some) organisations for years. What has changed though is the ease with which work can extend so deeply into employees' personal time and spaces. BlackBerries have been successful because they do allow people to work anywhere, anytime. But because they allow people to work anywhere, anytime, they reinforce negative aspects of organisational cultures that encourage overwork. 


\section{References}

Allen, D. K. and M. Shoard (2005) 'Spreading the Load: Mobile Information and Communications Technologies and Their Effect on Information Overload', Information Research, vol. 10, no. 2, Paper 227, pp. non-paginated.

Anonymous (2004) 'The Life of a BlackBerry Widow', tech dirt, Available at: http://www.techdirt.com/articles/20040503/0224203_F.shtml.

Argyris, C. A. and D. A. Schön (1978) Organizational Learning: A Theory of Action Perspective, Addison-Wesley, Reading, MA.

BlackBerry Blackout (2005) Wall Street Journal, 30 November, p. A18.

BlackBerry Press Releases (2005) 'Telefónica Móviles and Research in Motion to Launch BlackBerry across Latin America', Available at: http://www.blackberry.com/news/press/2005/pr-30 11 2005-02.shtml.

Brown, B., N. Green and R. Harper (eds.) (2002) Wireless World: Social and Interactional Aspects of the Mobile Age, London, Springer-Verlag.

Buelens, M. and S. A. Y. Poelmans (2004) 'Enriching the Spence and Robbins' Typology of Workaholism: Demographic, Motivational and Organizational Correlates', Journal of Organizational Change Management, vol. 17, no. 5, pp. 440-458.

Burke, R. J. (2001) 'Workaholism in Organizations: The Role of Organizational Values', Personnel Review, vol. 30, no. 5/6, pp. 637-645.

Burke, R. J. (2004) 'Introduction: Workaholism in Organizations', Journal of Organizational Change Management, vol. 17, no. 5, pp. 420-423.

Burke, R. J., A. M. Richardsen and M. Martinussen (2004) 'Workaholism among Norwegian Senior Managers: New Research Directions', International Journal of Management, vol. 21 , no. 4, pp. 415-426.

Chesley, N. (2005) 'Blurring Boundaries? Linking Technology Use, Spillover, Individual Distress, and Family Satisfaction', Journal of Marriage and Family, vol. 67, no. 5, pp. 1237-1248.

Connors, E. (2006) 'BlackBerry in Full Flight in Australia', Australian Financial Review, 22 February, p. 52.

Cousins, K. C. and D. Robey (2005) 'Human Agency in a Wireless World: Patterns of Technology Use in Nomadic Computing Environments', Information and Organization, vol. 15, no. 2, pp. 151-180.

Du Gay, P., S. Hall, L. Janes, H. Mackay and K. Negus (1997) Doing Cultural Studies: The Story of the Sony Walkman, The Open University/SAGE, London.

Duxbury, L. and C. Higgins (2001) Work-Life Balance in the New Millennium: Where Are We? Where Do We Need to Go? Canadian Policy Research Network.

Duxbury, L., C. Higgins and D. Coghill (2003) Voices of Canadians: Seeking Work-Life Balance. Human Resources Development Canada.

Duxbury, L., C. Higgins and C. Lee (1994) 'Work-Family Conflict: A Comparison by Gender, 
Family Type, and Perceived Control.' Journal of Family Issues, vol. 15, no. 3, pp. 449466.

Economist Staff (2005) 'The CrackBerry Backlash', The Economist, vol. 375, no. 8432, pp. 78.

Fortunati, L. (2002) 'The Mobile Phone: Towards New Categories and Social Relations', Information, Communication \& Society, vol. 5, no. 4, pp. 513-528.

Gilder, G. (1993) 'Metcalf's Law and Legacy', Forbes ASAP, 13 September.

Gordon, J. (2002) 'The Mobile Phone: An Artefact of Popular Culture and a Tool of the Public Sphere', Convergence, vol. 8, no. 3, pp. 15-26.

Govindaraju, M. and D. Sward (2005) 'Effects of Wireless Mobile Technology on Employee Work Behavior and Productivity: An Intel Case Study', in C. Sørensen et al. (eds.) Designing Ubiquitous Information Environments: Socio-Technical Issues and Challenges, New York: Springer, pp. 349-351.

Haddon, L. (ed.) (1997) Communications on the Move: The Experience of Mobile Telephony in the 1990s, Brighton, Sussex, CULCOM.

Hallowell, E. (2005) 'Overloaded Circuits: Why Smart People Underperform', Harvard Business Review, vol. 83, no. 1, pp. 54-62.

Hatch, M. J. (1993) 'The Dynamics of Organizational Culture', Academy of Management Review, vol. 18 , no. 4, pp. 657-693.

Higgins, C. and L. Duxbury (2005) 'Saying "No" In a Culture of Hours, Money and Non-Support', Ivey Business Journal Online, vol., no., pp. 1-5.

Humphreys, L. (2005) 'Cellphones in Public: Social Interactions in a Wireless Era', New Media \& Society, vol. 7, no. 6, pp. 810-833.

Jarvenpaa, S. L., K. R. Lang and V. K. Tuunainen (2005) 'Friend or Foe? The Ambivalent Relationship between Mobile Technology and Its Users', in C. Sørensen et al. (eds.) Designing Ubiquitous Information Environments: Socio-Technical Issues and Challenges, New York: Springer, pp. 29-42.

Katz, J. E. (2003) Machines That Become Us: The Social Context of Personal Communication Technology, Transaction Publishers, New Brunswick, N.J.

Katz, J. E. and M. A. Aakhus (2002) Perpetual Contact: Mobile Communication, Private Talk, Public Performance, Cambridge University Press, Cambridge.

Ling, R. S. (2004) The Mobile Connection: The Cell Phone's Impact on Society, Morgan Kaufmann, San Francisco, CA.

Maiden, M. (2006) 'Midnight Watchman', Sydney Morning Herald, 14 April, p. 31.

Mazmanian, M. A., W. J. Orlikowski and J. Yates (2005) 'Crackberries: The Social Implications of Ubiquitous Wireless E-Mail Devices', in C. Sørensen et al. (eds.) Designing Ubiquitous Information Environments: Socio-Technical Issues and Challenges, New York: Springer, pp. 337-344.

Middleton, C. A. and W. Cukier (2006, in press) 'Is Mobile Email Functional or Dysfunctional? Two Perspectives on Mobile Email Usage', European Journal of Information Systems, vol. 15, no. 3, pp. 
Middleton, C. A., H. Scheepers and W. Cukier (2005) 'Exploring the Contradictions of Mobility: A Case Study of BlackBerry Users in Canada', in J. Y. L. Thong and K. Y. Tam (eds.) Proceedings of the Hong Kong Mobility Roundtable, Hong Kong: HKUST, pp. 299-309.

Morgan, G. (1997) Images of Organization, 2nd edition, Sage, Thousand Oaks, CA.

Nah, F. F.-H., K. Siau and H. Sheng (2005) 'The Value of Mobile Applications: A Utility Company Study', Communications of the ACM, vol. 48, no. 2, pp. 85-90.

Nyíri, K. (2003) Mobile Democracy: Essays on Society, Self and Politics, Passagen Verlag, Vienna.

Oksman, V. and J. Turtiainen (2004) 'Mobile Communication as a Social Stage: Meanings of Mobile Communication in Everyday Life among Teenagers in Finland', New Media \& Society, vol. 6, no. 3, pp. 319-339.

Parks, B. (2006) 'Addiction, Withdrawal and the BlackBerry', The Star-Ledger, 29 January, p. 1.

Peters, O. and S. B. Allouch (2005) 'Always Connected: A Longitudinal Field Study of Mobile Communication', Telematics and Informatics, vol. 22, no. 3, pp. 239-256.

Reguly, E. (2006) 'RIM on Edge of Big Global Growth Story', The Globe and Mail, 7 March, p. B2.

Rick Mercer Report (2006) 'BlackBerry Helmet', Available at: http://throwawayyourtv.com/2006/03/blackberry-helmet.html.

Schein, E. H. (2004) Organizational Culture and Leadership, 3rd edition, Jossey-Bass, San Francisco.

Senge, P. M. (1990) The Fifth Discipline: The Art and Practice of the Learning Organization, Currency Doubleday, New York.

Sharma, D. C. (2004) 'RIM Takes BlackBerry to India', CNET News.com, Available at: http://news.com.com/RIM+takes+BlackBerry+to+India/2100-1041 3-5417375.html.

Sørensen, C. and D. Gibson (2004) 'Ubiquitous Visions and Opaque Realities: Professionals Talking About Mobile Technologies', Info - The journal of policy, regulation and strategy for telecommunications, vol. 6, no. 3, pp. 188 - 196.

Staw, B. M. (1981) 'The Escalation of Commitment to a Course of Action', Academy of Management Review, vol. 6, no. 4, pp. 577-587.

Terry, J. A. (2006) 'CrackBerry' Use Increases Despite Patent Dispute', The State Journal, 21 April, p. T6.

Top Tech News (2006) 'Research in Motion Wins BlackBerry Patent Dispute in UK', Available at: http://www.toptechnews.com/news/RIM-Wins-UK-PatentDispute/story.xhtml?story id=0320037X65DS.

Van Den Berg, P. T. and C. P. M. Wilderom (2004) 'Defining, Measuring, and Comparing Organisational Cultures', Applied Psychology-an International Review-Psychologie Appliquee-Revue Internationale, vol. 53, no. 4, pp. 570-582.

Waldie, P. (2006) 'RIM Shares Rise on Upbeat Results', Globe and Mail, 30 June. 
1 'BlackBerry' is a registered trademark of Research in Motion (RIM).

${ }^{2}$ Refer to www.rim.com/news/press/index.shtml for quarterly updates of subscriber numbers. As of June 2006 subscriber numbers were estimated at approximately 5.5 million. It is estimated that RIM has $75 \%$ of the US mobile email market (Waldie, 2006).

${ }^{3}$ One of the appeals of the BlackBerry is its seamless international roaming ability. Users must pick a provider that supports this service. With this service, simply turning on the device starts the flow of email, from any worldwide location within network reach.

${ }^{4}$ It is noted that the BlackBerry is most widely adopted and best known in the United States and Canada (Reguly, 2006). In the past couple of years it has gained a foothold among mobile users in the United Kingdom (Top Tech News, 2006) and Australia (Connors, 2006). At the time of writing, the BlackBerry was not widely used in European or Asian markets, where 3G mobile phones often provide more functionality than BlackBerries. Service has been available in India since 2004 (Sharma, 2004). There is limited BlackBerry adoption in South America, with service becoming available in thirteen countries in 2006 (BlackBerry Press Releases, 2005). A full list of products available around the world is found online at http://www.rim.net/products/handhelds/index.shtml.

${ }^{5}$ Examples can be found by searching databases including ABI/Inform, Factiva or LexisNexis, using search terms like 'BlackBerry and Crackberry.'

${ }^{6}$ It is assumed from the use of the word 'Crackberry' in the article title that the 'wireless email devices' studied were BlackBerries, but this is not stated explicitly.

${ }^{7}$ Hatch (1993) provides a synthesis of research criticizing Schein's approach to organisational culture. She proposes a reformulation of his model incorporating symbols, and focusing on the dynamics of culture, but notes that Schein's model 'continues to have relevance' (p. 658). Cultural analysis is used in this paper as a diagnostic tool to expose shared understandings and underlying assumptions embedded in the adoption of an artifact. Schein's model is well-suited for this purpose.

${ }^{8}$ An interesting extension of work on BlackBerry usage would be to consider the personalities of individual adopters, with a specific focus on traits that indicated workaholism. Work by Burke and colleagues (Burke, 2001; Burke, 2004; Burke, Richardsen \& Martinussen, 2004) and Buelens and Poelmans (2004) could provide starting points for this line of investigation.

${ }^{9}$ Double loop learning involves questioning the norms in which an organisation operates. A double loop learning response may involve challenging organisational norms, whereas a single loop process operates within existing norms (Morgan, 1997, Chapter 4). 